\title{
Leaving no one behind: Community Management of At-risk Mothers and Infants under six months (MAMI) in the context of COVID-19 in Gambella refugee camps, Ethiopia
}

\section{Authors(s)}

Ritu Rana ${ }^{1 *}$, Hatty Barthorp ${ }^{2}$ and Mary T Murphy ${ }^{3}$

\section{Affiliation(s)}

${ }^{1}$ Nutrition Research Advisor, MAMI, GOAL Global, Carnegie House, Dun Laoghaire, Co. Dublin, A96 C7W7 Ireland, rrana@goal.ie

${ }^{2}$ Global Nutrition Advisor, GOAL Global, Carnegie House, Dun Laoghaire, Co. Dublin, A96 C7W7 Ireland, hbarthorp@goal.ie

${ }^{3}$ Refugee Program Manager, GOAL Ethiopia, 508, Yeka Sub city, Kebele 17, Woreda 9, Addis Ababa, Ethiopia, maryt@et.goal.ie

\section{* Corresponding author}

Ritu Rana 


\section{ABSTRACT}

Refugees are at an increased risk of contracting Coronavirus disease (COVID-19) due to their suboptimal living environment and inadequate access to healthcare services. As refugeehosting countries are preparing to prevent and contain the spread of COVID-19 infections by diverting healthcare efforts, it is equally important to prevent the collapse of existing lifesaving services, including those provided during the first 1,000 days (nutrition services from conception to a child's second birthday).

Recently, many international organisations, including United Nations agencies, have published guidance documents for programming in refugee context. Similarly, there is global guidance available for nutrition programs in the context of COVID-19, such as -infant and young child feeding, management of child wasting, and nutrition information management; however, no specific guidance is available for community management of nutritionally at-risk mothers and infants under six months (MAMI).

In response to the major refugee influx, mainly women and children, from South Sudan, GOAL, an international humanitarian response organisation, is implementing a MAMI program since 2014. GOAL believes, despite COVID-19 context, it is critical to continue the MAMI program with adaptive measures to prevent and manage malnutrition among at-risk mothers and infants. In this regard, considering available international guidelines, both nutrition and refugee context-specific, GOAL has developed its own guidelines for the refugee population.

In this article, we present GOAL Ethiopia's COVID-19 response within nutrition support services, for the South Sudanese refugees, focused on at-risk mothers with infants under six months, living in two Gambella refugee camps. We believe our guidelines will also be helpful for other organisations implementing MAMI in different contexts.

\section{Keywords}

COVID-19, refugees, malnutrition, infants, guidelines, MAMI

\section{Acknowledgment}

The authors would like to thank the DropBox Foundation for funding the progressive innovations during 2019 in collaboration with the Bureau of Population, Refugee, and Migration (BPRM) - United States Department of State, European Commission Humanitarian Office (ECHO), the United Nations High Commission for Refugees (UNHCR) and the United Nations Children's Fund (UNICEF). 


\section{INTRODUCTION}

Globally, Coronavirus disease (COVID-19) has affected around 215 countries, with 134 refugee-hosting countries already reporting local transmission (UNHCR 2020a). On March 11, 2020, the World Health Organisation (WHO) officially declared that COVID-19 can be characterised as a pandemic (WHO 2020c). It is estimated that the pandemic will disproportionately affect the world's most vulnerable populations, including refugees (Spiegel 2020). Refugees are at increased risk of contracting infectious diseases, due to their often suboptimal living environment, including overcrowded conditions and limitations around access to basic sanitation (Kluge et al. 2020). Therefore, in light of COVID-19 preparedness and response, it is important that we must not leave behind, rather actively include, measures to support these vulnerable populations.

Ethiopia is one of the largest refugee hosting countries in Africa- with 763,827 registered refugees (as of May 2020) across eight locations (UNHCR 2020f). Gambella is one of the largest regions with around 41\% (316,807, as of May 2020) of the total refugee population living in camps, of which 88\% are women and children (UNHCR 2020e, $\underline{\text { b }) . ~ T h i s ~ r e g i o n ~ h a s ~}$ seven camps and two of these - Kule and Tierkidi are supported by GOAL Ethiopia, in partnership with the United Nations High Commissioner for Refugees (UNHCR), Agency for Refugee and Returnee Affairs (ARRA), World Food Programme (WFP), Medicine Sans Frontiers (MSF), and International Rescue Committee (IRC) (Figure 1). Since 2014, in response to the major refugee influx from South Sudan, GOAL Ethiopia has provided lifesaving and life-sustaining services to nutritionally at-risk mothers and infants under six months, as part of a wider package of preventative and curative nutrition interventions (Burrell and Barthorp 2020).

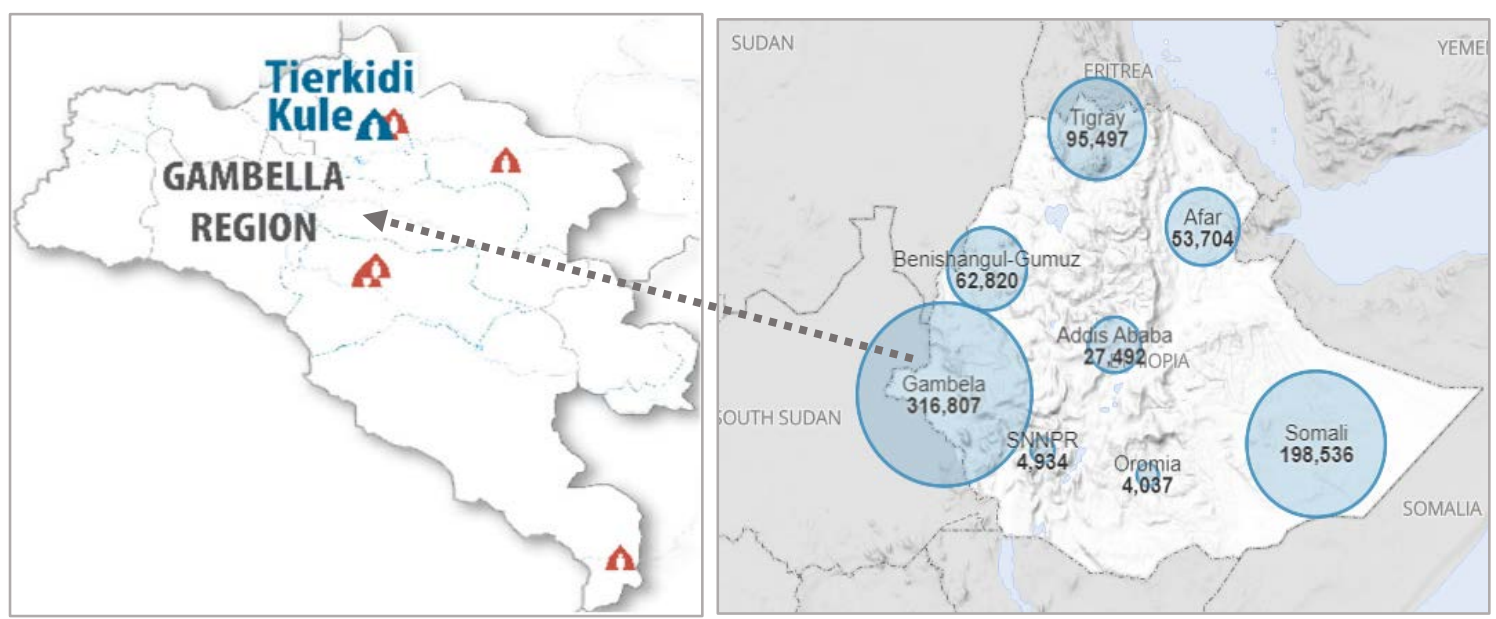

Figure 1: Gambella region and GOAL’s camp sites (UNHCR 2020c, $\underline{\text { d) }}$

GOAL is an international humanitarian response agency established in Ireland over 40 years ago. GOAL believes in a world where poverty no longer exists, where vulnerable communities are resilient, where barriers to well-being are removed and where everyone has equal rights and opportunities. GOAL works in 13 countries across Africa, Latin America, and the Middle East, with headquarter in Ireland (also known as GOAL Global). GOAL Ethiopia, based in Addis Ababa, is one of its country offices in the African region. In this article, we aim to present GOAL's COVID-19 response within nutrition support services, for the South Sudanese refugees, focused on women with infants under six months, living in two Gambella refugee camps, Kule and Tierkidi. 


\section{MAMI program for vulnerable refugee population}

GOAL's management of at-risk mothers and infants under six months (MAMI) program is nested within the maternal, infant, and young child feeding (MIYCF) program (a first 1,000 days of life service). MAMI, unlike many other public health programs, brings together both preventive and curative services for nutritionally at-risk mother-infant pairs. These services are provided using an adaptive version of the MAMI tool (this tool is now redesigned into MAMI care pathway) (ENN et al. 2018).

The tool provides a community health worker with a format to assess, classify, and manage nutritionally at-risk mothers and infants under six months. The assessment section includes triage (signs and symptoms for referral to inpatient care), feeding assessment, anthropometric/nutritional assessment, and maternal mental health assessment. This is followed by classifying each of the assessment criteria as high risk (red), moderate risk (orange), and low risk (green). Management includes urgent referral to an inpatient facility if classified as high risk, enrolment in an outpatient MAMI program if classified as moderate risk, or home-based care if identified as low risk.

For identification of cases, community level screening is performed using specially designed, reversible mid-upper arm circumference (MUAC) tapes (Figure 2a-b) (Burrell and Barthorp 2020). Side a is used to help identify infants under six months at heightened risk of mortality due to malnutrition ( $<11.0 \mathrm{~cm}$ for $0-6$ weeks and $<11.5 \mathrm{~cm}$ for $7-25$ weeks) and side $\mathrm{b}$ is used for mothers to classify severity of malnutrition $(<23 \mathrm{~cm})$. Side $b$ of these tapes are also used for other nutrition services for older children from 6 months to 5 years- Outpatient Therapeutic Program (OTP) and Supplementary Feeding Program (SFP). There are also two versions - colour-coded enumerated ones for health workers and non-enumerated, simple colour-coded for home-based family use (Burrell and Barthorp 2020). The tapes help support case identification in the community and referral to appropriate care services. Community Outreach Agents (COAs) also use their skills and training to identify other potentially problematic behaviours or practices, where the mother-infant pair would benefit from enrolment within the MAMI program.

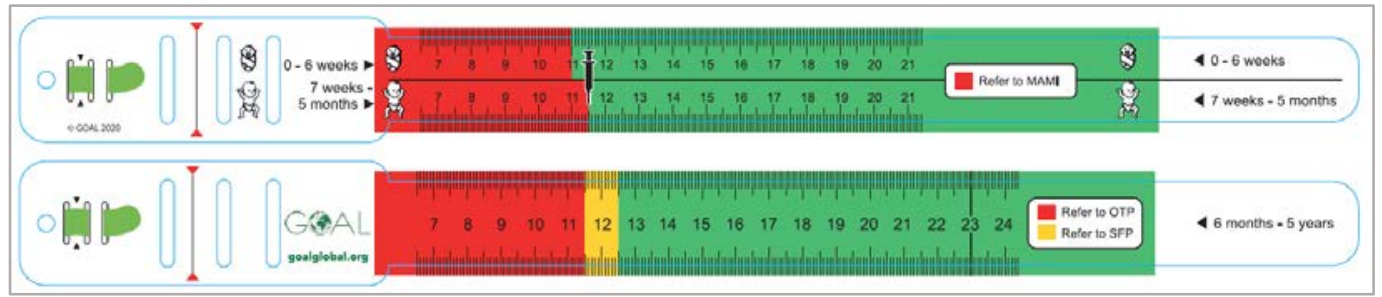

Figure 2a: Enumerated, colour-coded reversible MAMI-MUAC tape, for health workers (top - infants $<6$ months and bottom - children 6 months to 5 years and mothers)

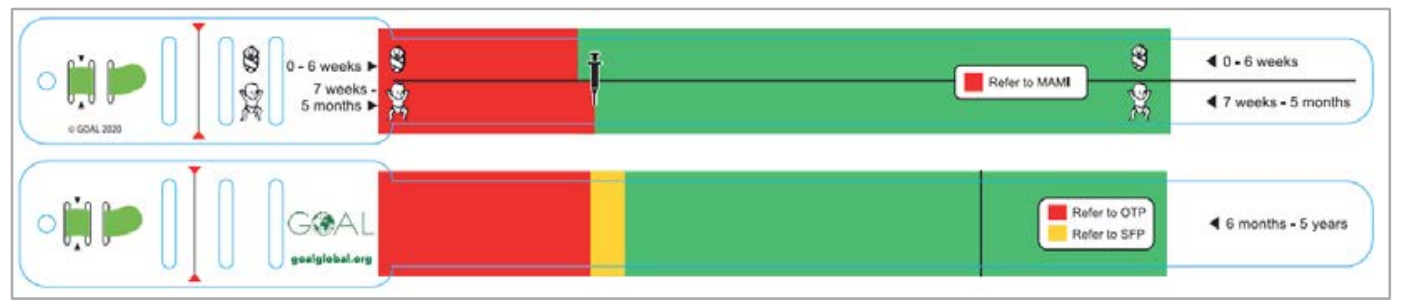

Figure 2b: Non-enumerated reversible MAMI-MUAC tape, for family members (top infants $<6$ months and bottom - children 6 months to 5 years and mothers) 
Assessment, classification, and subsequently enrolment is based on the risk status of the mother-infant pair, which is assessed using ABCD criteria- Anthropometry, Breastfeeding, Clinical, and Depression/anxiety. Each of these elements are assessed and subsequently a classification is awarded. If the infant/mother is deemed high risk with clinical condition (medical complications), or severe depression (psychological problems), they would be referred for more specialised and intensive in-patient assessment and care.

If moderate risk is identified using anthropometry, feeding problems, or maternal mental health assessment, they would be classified as suitable for outpatient MAMI care. This is followed by managing the mother-infant cases, in some cases daily, but more commonly, though weekly follow up visits for i) monitoring the risk status, and ii) providing tailored counselling and support (Table 1).

The pair are discharged if the mother-infant both are outside the at-risk criteria. Note: prospectively, the program will shift from use of 'discharge', to a de-escalated, monthly follow up, once there is no longer identifiable risk, until six months. The program components are recorded and monitored digitally using a mobile-based application (CommCare) and analytical dashboards (PowerBI), respectively. This real-time monitoring and surveillance system are managed by a Monitoring, Evaluation, Accountability, and Learning (MEAL) team in the GOAL Ethiopia country office (Addis Ababa) and the reports are shared with the Refugee Program Manager (Gambella) for timely action.

\section{Nutrition programs and COVID-19}

Given the exponential growth of COVID-19 cases worldwide, it is understandable that much of the effort is diverted towards its containment, upgrading and modification of healthcare services. However, it is equally important to prevent the collapse of existing lifesaving services, such as those provided during the first 1,000 days (Headey and Ruel 2020). Currently, as summarised in Box 1, there is global guidance available for other nutrition programs- 'Infant and Young Child Feeding in the Context of COVID-19', 'Management of Child Wasting in the Context of COVID-19', and 'Nutrition Information Management, Surveillance, and Monitoring in the Context of COVID-19' (UNICEF, GNC, and GTAM 2020c, b, a), but nothing for MAMI.

\section{Refugees and risk of COVID-19}

Refugees are potentially at an increased risk of contracting COVID-19. Factors, such as overcrowded camp conditions, limitations around water, sanitation and hygiene (WASH) facilities, restricted access to adequate and timely health information, and imperfections within the available healthcare service due to language, financial, administrative, and legal barriers, all contribute to increased vulnerability (Kluge et al. 2020, The Lancet 2020). Furthermore, recommended COVID-19 public health measures, such as quarantine, selfisolation, social distancing, and frequent handwashing are extremely difficult to implement in camp settings (Kluge et al. 2020). Thus, both usual measures to respond as well as a tailored preparedness plan is needed to avoid a COVID-19 outbreak in refugee camps.

\section{Situation in Gambella refugee camps}

Although Ethiopia has 1,636 confirmed COVID-19 cases (as of $4^{\text {th }}$ June 2020), with the index case first being recorded on the $13^{\text {th }}$ March, there have been no cases reported in the Gambella region, according to UNHCR weekly report (as of $18^{\text {th }}$ May 2020) (UNHCR 2020g, Johns Hopkins University (JHU) 2020). The two refugee camps are in very remote locations with limited healthcare facilities. There are no hospitals (tertiary care facility) in the 
Table 1: Program enrolment, management, and discharge components for outpatient MAMI Care

\section{ENROLMENT (if ANY of the below criteria is applicable)}

Breastfed infant (no medical complication):

Multiple births / LBW/ Premature/ Orphan/ Mother sick and unable to care for infant $=$ Yes

o Infant with anthropometric criteria considered 'at risk' (MUAC $<11 \mathrm{~cm}$ in infants $<7$ weeks / $<11.5 \mathrm{~cm} 7-25$ weeks or WAZ $<-2$ for $0-5$ month) $=$ Yes

o Infant with recent moderate weight loss, failure to gain weight $=$ Yes

o Infant with visible moderate wasting $=$ Yes

o Infant with feeding problems (not well attached or poor sucking, $<8$ feeds/24hrs, or mixed feeding $=$ Yes

o Mother with feeding concerns or breast conditions $=$ Yes

o Mother with mild or moderate anxiety, depression or stress impacting daily life $=$ Yes

o Mother with MUAC $<23 \mathrm{~cm}=$ Yes
Non-Breastfed infant (no medical complication):

o Multiple births / LBW/ Premature/ Orphan/

Mother sick and unable to care for infant $=$ Yes

o Infant with anthropometric criteria considered 'at risk' (MUAC $<11 \mathrm{~cm}$ in infants $<7$ weeks / < $11.5 \mathrm{~cm} \mathrm{7-25}$ weeks or WAZ $<-2$ for $0-5$ month) $=$ Yes

o Infant with recent moderate weight loss, failure to gain weight $=$ Yes

o Infant with visible moderate wasting $=$ Yes

o Infant without an Acceptable, Feasible, Affordable, Sustainable and Safe (AFASS) source of breast milk substitute $(\mathrm{BMS})=$ Yes

o Infant with feeding problems (consuming $<500 \mathrm{ml}$ of BMS/24hrs, refusing feeds, or mixed feeding = Yes

o Mother with concerns about feeding $=$ Yes

o Mother with mild or moderate anxiety, depression or stress impacting daily life $=$ Yes

\section{MANAGEMENT (weekly follow-up visits)}

\begin{tabular}{|l|l|}
\hline Anthropometry & $\begin{array}{l}\text { Infant: Bilateral pitting oedema, MUAC, weight, weight gain, weight-for-age z score } \\
\text { (WAZ), and length } \\
\text { Mother: Bilateral pitting 0edema, MUAC }\end{array}$ \\
\hline Clinical examination & Infant: Temperature, respiratory rate, dehydrated, anaemia, and episode of sickness \\
\hline Monitoring feeding & $\begin{array}{l}\text { Breastfeeding status, well attached, suckling effectively, frequency of breastfeeds, } \\
\text { consumes any of the following: water, other liquids or foods, clinically well and alert } \\
\text { to take feed, mother is confident with infant condition and breastfeeding, and if non- } \\
\text { breastfed: receiving appropriate Breast Milk Substitute (BMS) }\end{array}$ \\
\hline Maternal follow up & Mother well enough to care for infant, and mental health status \\
\hline $\begin{array}{l}\text { Counselling and } \\
\text { support }\end{array}$ & $\begin{array}{l}\text { Breastfeeding support, supplementary suckling support, social support } \\
\text { (family/community counselling), and non-breastfeeding support }\end{array}$ \\
\hline
\end{tabular}

\section{DISCHARGE (if ALL of the below criteria are applicable)}

\section{Breastfed Infant:}

o Infant breastfeeding well=Yes

o Infant consumes any water, other liquids or foods $=$ No

o Infant clinically well and alert $=$ Yes

o Infant demonstrates adequate weight gain/positive growth curve $/$ thriving $=$ Yes

o Mother confident with infant condition and breastfeeding $=$ Yes

o Mother adequately nourished (MUAC > 21cm) $=$ Yes

o Mother clinically well enough to care for infant $=$ Yes

o Mother with no psychological problems $=$ No

\section{Non-breastfed infant:}

o Infant provided with appropriate quantity of AFASS BMS $=$ Yes

o Infant consumes any water, other liquids or foods $=$ No

o Infant clinically well and alert=Yes

o Infant demonstrates adequate weight gain / positive growth curve $/$ thriving $=$ Yes

o Mother confident with infant condition and feeding $=$ Yes

o Mother adequately nourished $($ MUAC $>21 \mathrm{~cm})=$ Yes

o Mother clinically well enough to care for infant = Yes

o $\quad$ Mother with no psychological problems $=$ No 
Box 1: Key messages from global nutrition guidance (UNICEF, GNC, and GTAM 2020a, $\underline{b}$, c) in the context of COVID-19

1. Programmes and services to protect, promote and support optimal breastfeeding (early and exclusive) should remain a critical component of the programming and response.

2. Mothers with suspected or confirmed COVID-19 and isolated at home should be advised to continue recommended feeding practices with necessary hygiene precautions during feeding.

3. Full adherence to the International Code of Marketing of Breast-milk Substitutes and subsequent WHA resolutions (including WHA 69.9 and the associated WHO Guidance on ending the inappropriate promotion of foods for infants and young children) in all contexts in line with the recommendations of Infant Feeding in Emergencies Operational Guidance.

4. Intensify the public awareness, protection, promotion, and support of appropriate and safe feeding for all breastfed and non-breastfed children and use all opportunities to include hygiene messages, key messages on COVID-19 symptoms, and Infection, Prevention and Control (IPC) measures.

5. Intensify pre-positioning (with a minimum buffer stock of 2 months) of essential commodities for nutrition programming and routine medicinal supplies at national, health facility and community level in anticipation of supply chain disruptions.

6. Intensify efforts to strengthen the capacity of mothers and caregivers to detect and monitor their children's nutritional status using low-literacy/numeracy tools including Mid-Upper Arm Circumference (MUAC) tapes.

7. Strengthen real-time monitoring and surveillance systems for child wasting with the use of mobile technologies to inform response options and allocation of resources.

8. In line with overall guidance to limit the spread of COVID-19 calls for minimal physical contact, avoid data collection activities that involve close contact between individuals. This includes mass screenings, household visits, population-based surveys (i.e. coverage, SMART, MICS, DHS, etc.) that involve in-person interaction until coordination mechanisms or governments deem safe to do so.

9. Initiate efforts to build capacity of community health workers to collect nutrition data on malnutrition at the community level using virtual training methods on no-touch assessments, mobile data collection or web-based surveys as examples.

10. Initiate discussions on potential options to track the number of undernourished children and other vulnerable population groups in the context of COVID-19, for example using mobile technology for interviews or sharing self-screening data through SMS etc.

camps, but there are health posts and health centres where preventive and basic primary curative services are provided. Refugees here are permitted to access the host communities' hospitals, but these facilities are already overloaded supporting Ethiopia's national population, and the hospitals in this area have no intensive care units (ICUs) or ventilators. Therefore, access to health care for refugees is a major vulnerability.

Our main concern is the high risk of COVID-19 transmission due to the large number of refugees living together. While GOAL is ensuring that our current humanitarian programs supporting nutrition, shelter and sanitation continue, we are also doing COVID-19 awareness-raising, providing extra handwashing facilities and distributing essential supplies such as soap. In addition, the refugees are being encouraged to social distance, but the reality is that the household shelters are crowded. Many families share one sleeping space, making social and physical distancing practically impossible. There is no electricity supply and no household televisions. Some have solar lamps and solar radios, but generally, the refugees are reliant on information from organisations such as GOAL and others operating in the camps.

\section{COVID-19 guidelines specific to refugee context}

Fortunately, there are numerous guidelines available that can be adapted in a refugee context. These include: 'Addressing mental health and psychosocial aspects of COVID-19', 'Water, sanitation, hygiene and waste management for COVID-19', 'Rational use of personal protective equipment for coronavirus disease (COVID-19) and considerations during severe shortage', and 'Interim Guidance scaling-up COVID-19 outbreak readiness and response 
operations in humanitarian situations including camps and camp-like settings' (IASC 2020, WHO 2020b, a, IFRC et al. 2020).

\section{Challenges posed by COVID-19}

Unlike other emergency responses, where response teams can travel from their home country to the affected country to provide support, with COVID-19, the response is limited to the available in-country support. Thus, in Ethiopia, with restrictions on countrywide travel, GOAL's response is focused on prevention. With the restriction of movement, GOAL staff are staying in their current areas of operation and not travelling within the country to minimize the spread of COVID-19. The MAMI program in Gambella refugee camps is remotely supported by the Addis Ababa-based country team and by headquarter staff in Dublin. However, communication is hampered by sporadic mobile and internet access.

\section{GOAL's adaptation to MAMI programming for refugee population in the context of COVID-19}

Over the past year, GOAL has screened infants under six months over 3,000 times, and managed 138 at-risk mother-infant pairs through the MAMI program. Of the 138 motherinfant pairs, around $80 \%$ of infants and $20 \%$ of mothers were classified as malnourished, based on anthropometric markers. Around 22\% of mothers had multiple births, $19 \%$ of infants had recent weight loss, and $12 \%$ of infants had breastfeeding difficulty. Additionally, $9 \%$ of mothers felt they are unable to care adequately for the baby, $5 \%$ of mothers had moderate depression, and $4 \%$ of infants were orphans. Younger infants ( $<6$ months) are more vulnerable to morbidity and associated mortality compared to older infants and children (Kerac and McGrath 2018). Furthermore, refugee camp settings within a harsh climate including overcrowding, limited shelter and water services, poor hygiene and sanitation conditions, and limited access to care, increases their inhabitant's vulnerability. Therefore, it is critical, despite the COVID-19 context, to continue the MAMI program with adaptive measures to prevent and manage these at-risk infants (including support for their mothers). In this regard, considering available international guidelines (nutrition and refugee contextspecific), GOAL has developed its own guidelines for the Gambella refugee camp- these are presented in Box 2 and Figure 3.

\section{Box 2: GOAL's guidelines for MAMI programming (adaptation to COVID-19)}

1. Suspend all community group-support sessions in line with government restrictions.

2. Intensify public awareness around protection, promotion and support for optimal feeding for all breastfed and non-breastfed infants.

2.1. This could be achieved through radio, posters, public messaging, text, etc.

2.2. Global guidance is that early and exclusive breastfeeding (EBF) for the first six months and ageappropriate and safe complementary feeding practices should remain a focus of public health messaging.

2.3. Mothers and/or infants with suspected or confirmed COVID-19 should be advised to continue with recommended feeding practices, using necessary hygiene precautions. This includes EBF if the mother is well enough to continue feeding in addition to the use of respiratory hygiene (covers her mouth whilst feeding) and maintains strict handwashing. If she is too unwell to feed, please refer to the IYCF in the Context of COVID-19 Brief $30^{\text {th }}$ March for more details (UNICEF, GNC, and GTAM 2020a). At the same time, use of all opportunities to include hygiene messages, key COVID-19 messages and infection prevention-control (IPC).

3. Communicate protocols around social distancing and wider IPC measures and develop standard operating procedures that should be implemented and adhered to through adapted programming. This 
should include what personal protective equipment (PPE) should be made available to staff (facility and community) and increase the spacing between staff and/or beneficiaries to at least two (2) meters.

4. If necessary, simplify case identification, enrolment criteria, counselling and treatment protocols.

4.1. Modified case identification

4.1.1. Use Community Outreach Agents (COAs) to cascade messages into the community regarding simplified risk/case identification, based on A, B, C, D approach.

- $\quad$ If families using the MAMI-MUAC show an infant 'at risk' (red) - Anthropometry

- $\quad$ If mothers/carers have any Breastfeeding/feeding problems - Breastfeeding

- $\quad$ If the mother/carer thinks their child is sick, or - Clinical

- $\quad$ If the mother/carer is struggling to care for the child due to stress, anxiety or mild depression - Depression

4.1.2. They should seek support from COA who will refer them to the MAMI clinic for enrolment if necessary.

4.1.3. Print and display posters to support the A, B, C, D risk-identification criteria.

4.1.4. COAs to use MUAC for anthropometric case identification in the community, conducted either by the COA-if adequate PPE is provided and adhering to strict IPC measures or by family under observation if social distancing is being applied.

4.1.5. COAs to refer all new cases to MAMI clinic for more in-depth A, B, C, D assessment and support plan.

4.1.6. If MAMI clinic staff have adequate PPE, MUAC and WAZ measures could be maintained for new enrolments. All equipment should be disinfected before and after use - soap and water are deemed adequate to clean MUAC tapes.

4.2. Simplified enrolment protocols

4.2.1. Most enrolment protocols can be maintained using social distancing. Those that require closer contact i.e. MUAC, weight and vital signs assessments, can be maintained using adequate PPE. However, if contact is prohibited, the following adaptations can be made:

- $\quad$ MUAC measures can be taken by the carer with guidance, where the health worker can observe the colour outcome whilst respecting social distancing of 2 meter.

- To assess weight, infants can be placed on scales by the carer, then asked to stand back whilst the health worker reads the scale.

- $\quad$ Note: All equipment must be disinfected before and after use. MUACs can be wiped with soap/water.

- A breastfeeding assessment can be done whilst respecting social distancing.

- $\quad$ The clinical assessment can be conducted whilst respecting social distancing, merely by asking the carer questions about symptoms and observing the infant.

- The psychosocial assessment can also be done whilst respecting social distancing.

4.3. Simplified counselling and treatment protocols

4.3.1. All infant-mother/carers using facility-based MAMI service should have their temperature checked before entering the clinic.

4.3.2. Decentralise follow-up services from facility-based care to the community with home-based counselling and support for existing cases showing positive progress. This will help to reduce exposures between family groups.

4.3.3. Adapt beneficiary contact to reduce follow-up visits. It is advised that after new cases are enrolled at the MAMI clinic, COAs conduct weekly visits at the beneficiary’s homestead with the mother/carer. Every $4^{\text {th }}$ week, the pair should be advised to attend 1 x MAMI clinic appointment to enable infant weighing to assess how they are growing against their WAZ growth charts. For cases with positive growth i.e. they are tracking upwards on their growth charts at week 4 , health facility staff can communicate to the COA to reduce the frequency of home-based follow-ups to once every 2 weeks until they are no longer deemed at risk.

\begin{tabular}{|c|c|c|c|c|c|c|c|c|c|c|c|}
\hline \multicolumn{12}{|c|}{ Adaptations for follow-up visits } \\
\hline & Enrolment & $\begin{array}{l}1^{\text {st }} \\
\text { week }\end{array}$ & $\begin{array}{l}2^{\text {rd }} \\
\text { week }\end{array}$ & $\begin{array}{l}3^{\text {th }} \\
\text { week }\end{array}$ & $\begin{array}{l}4^{\text {th }} \\
\text { week }\end{array}$ & $\begin{array}{l}5^{\text {th }} \\
\text { week }\end{array}$ & $\begin{array}{l}6^{\text {th }} \\
\text { week }\end{array}$ & $\begin{array}{l}7^{\text {th }} \\
\text { week }\end{array}$ & $\begin{array}{l}8^{\text {th }} \\
\text { week }\end{array}$ & $\begin{array}{l}9^{\text {th }} \\
\text { week }\end{array}$ & $\begin{array}{l}10^{\text {th }} \\
\text { week }\end{array}$ \\
\hline $\begin{array}{l}\text { For } \\
\text { new } \\
\text { cases }\end{array}$ & $\begin{array}{l}\text { Enrolment at } \\
\text { MAMI clinic } \\
\text { by healthcare } \\
\text { staff }\end{array}$ & $\begin{array}{l}1^{\text {st }} \\
\text { home } \\
\text { visit by } \\
\text { COA }\end{array}$ & $\begin{array}{l}2^{\text {nd }} \\
\text { home } \\
\text { visit by } \\
\text { COA }\end{array}$ & $\begin{array}{l}3^{\text {rd }} \\
\text { home } \\
\text { visit by } \\
\text { COA }\end{array}$ & $\begin{array}{l}4^{\text {th }} \text { visit at MAMI } \\
\text { clinic } \\
\text { (weight assessment } \\
\text { by healthcare staff) }\end{array}$ & & & & & & \\
\hline \multicolumn{5}{|c|}{ Scenario 1: Cases improving at $4^{\text {th }}$ visit to MAMI clinic } & $\begin{array}{l}\text { Cases with positive } \\
\text { growth }\end{array}$ & & $\begin{array}{l}5^{\text {th }} \\
\text { home } \\
\text { visit by } \\
\text { COA }\end{array}$ & & $\begin{array}{l}6^{\text {th }} \\
\text { home } \\
\text { visit by } \\
\text { COA }\end{array}$ & & $\begin{array}{l}7_{\text {th }}^{\text {home }} \\
\text { visit by } \\
\text { COA }\end{array}$ \\
\hline \multicolumn{5}{|c|}{ 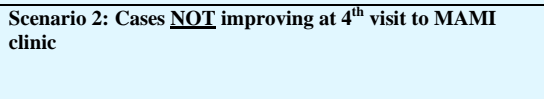 } & $\begin{array}{l}\text { Cases with growth } \\
\text { faltering }\end{array}$ & \multicolumn{6}{|c|}{$\begin{array}{l}\text { To continue with MAMI clinic visits until growth is observed. } \\
\text { Thereafter revert to home visits by COA for next } 3 \text { weeks } \\
\text { followed by } 4^{\text {th }} \text { week's visit at MAMI clinic for WAZ } \\
\text { assessment. }\end{array}$} \\
\hline
\end{tabular}


4.3.4. Only infants needing intensive support or existing cases showing signs of deterioration should be referred for follow up in the MAMI clinic. Signs of deterioration include, a) a visible deterioration in the physique of the infant, b) a MUAC measure moving from green (on previous assessment) to red, or if enumerated MUAC measures are being recorded by COA's with PPE, a fall in MUAC measure between weekly visits or c) clinical signs of deterioration noted by parents/carers. NB: Infants receiving BMS will need to attend MAMI clinics to receive re-supply on a weekly basis and thus can continue to be supported in clinic.

4.3.5. Reduce overcrowding in MAMI clinics through more frequent provision of facility-based services (e.g. from 1 to 5 days per week) for those needing to attend the clinic.

5. Intensify pre-positioning (with a minimum buffer stock of 2 months) of essential commodities for MAMI services; this might include MAMI-MUACs, IEC materials for facility and/or community-based use, BMS for non-BF infants without alternative options.

6. Include provision of hygiene kits for children and PLWs with IPC messaging.

7. Through use of the Family MAMI-MUAC approach, intensify efforts to strengthen the capacity of mothers/caregivers to detect and monitor their baby's nutritional status. This can be done through community-based trainings with small groups, respecting IPC measures - see family MUAC guidance note and IPC guidance. In addition, during COA interactions with the community, if new families/births are identified, where families do not already have MAMI-MUACs, provide clean tapes and orient caregivers on how to use the tape, how to check for kwashiorkor and what to do if 'red' markers/bilateral pitting oedema are observed. MAMI-MUACs can also be distributed through facility-based services for new or existing beneficiaries.

8. Full adherence to the International Code of Marketing of Breast-milk Substitutes and subsequent World Health Assembly (WHA) resolutions in line with recommendations in the infant and young child feeding in emergencies (IFE/IYCF-E) Operational Guidance (IFE Core Group 2017).

9. Adapt the MEAL plan and digital data tools if necessary, in collaboration with HQ (MAMI advisor).

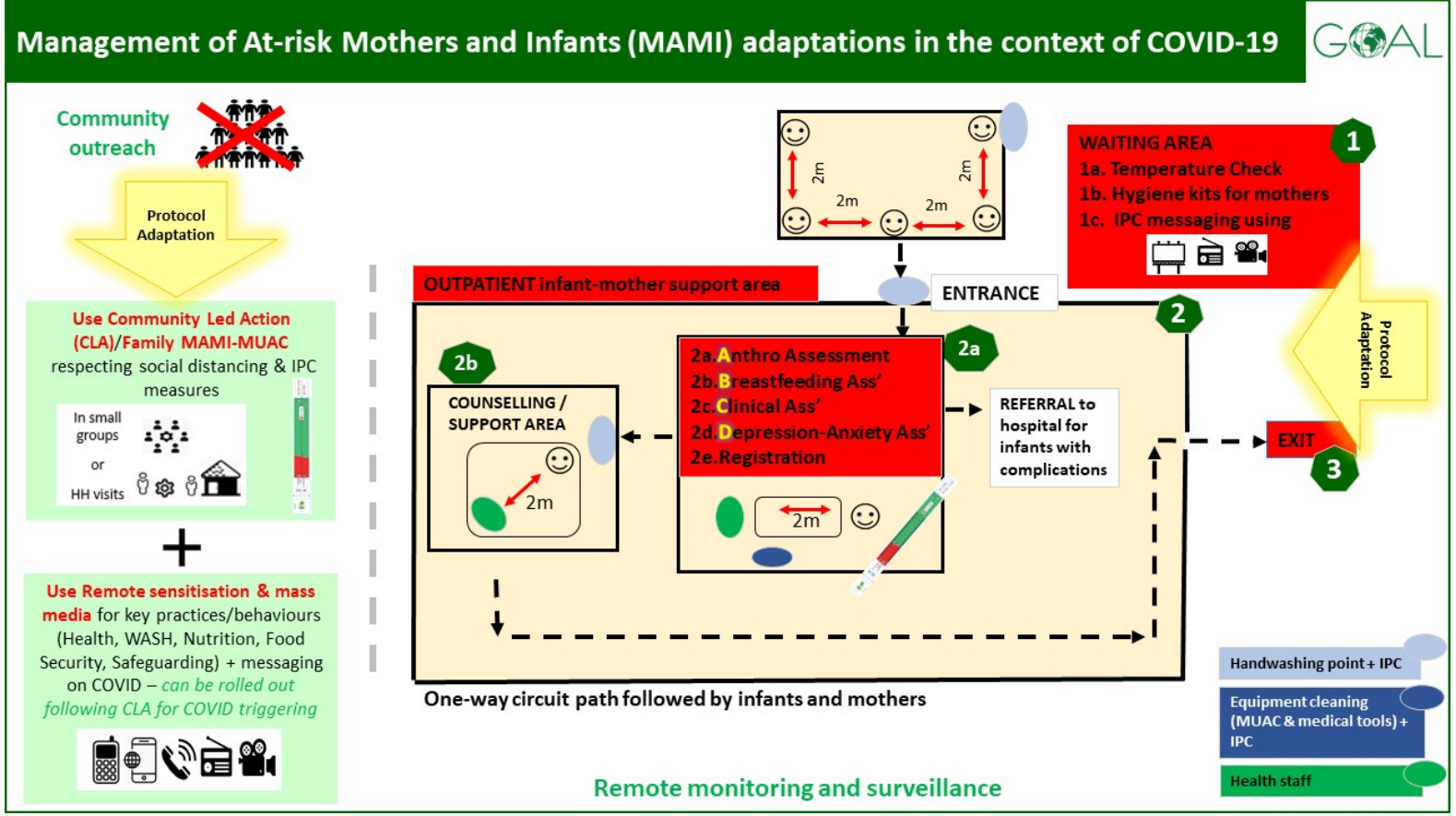

Figure 3: Poster for MAMI adaptations in the context of COVID-19

Unlike most low- and middle-income country settings, where organisational staff do have access to the internet and can access updates on global nutrition guidelines, refugee settings often lack, or have limited services. Due to poor internet connectivity, the GOAL HQ and GOAL Ethiopia team could not arrange a virtual training session for the Gambella camp 
staff- one of the limitations of working in remote settings. Thus, these guidelines are the only source of information available to GOAL Ethiopia's team in Gambella.

As Gambella staff prepare for the adaptive MAMI response, they have trained 112 COAs and around 1,289 mothers and caregivers to assess their child's nutritional status using nonenumerated MAMI-MUAC tapes. The real-time monitoring and surveillance system for MAMI has also been strengthened to a three-tier system- MAMI advisor (at headquarters), MAMI MEAL coordinator (at the country office), and MAMI supervisor (at Gambella).

\section{SUMMARY AND CONCLUSIONS}

GOAL's adapted MAMI guidelines serve as an important reference document for the Gambella refugee camp staff and serve as the best available resource. As recommended by global nutrition guidelines in the context of COVID-19, GOAL's MAMI program strengthens the capacity of mothers and caregivers to detect and monitor their child's nutritional status using the MAMI-MUAC tape. Our MAMI program uses real-time monitoring and surveillance systems with the use of mobile technology to inform response options - another key recommendation by global guidelines. We believe the above guidance will also be helpful for other organisations implementing MAMI in different contexts. Furthermore, countries with a high burden of malnutrition among infants under six months, such as countries in the southern region of Asia, can also refer to these guidelines and adapt as per their local context.

\section{List of abbreviations and acronyms}

$\begin{array}{ll}\text { ABCD } & \text { Anthropometry, Breastfeeding, Clinical, Depression/anxiety } \\ \text { AFASS } & \text { Acceptable, Feasible, Affordable, Sustainable and Safe } \\ \text { ARRA } & \text { Agency for Refugee and Returnee Affairs } \\ \text { BMS } & \text { Breast Milk Substitute } \\ \text { CLA } & \text { Community Led Action } \\ \text { COAs } & \text { Community Outreach Agents } \\ \text { COVID-19 } & \text { Coronavirus disease } \\ \text { DHS } & \text { Demographic and Health Survey } \\ \text { GNC } & \text { Global Nutrition Cluster } \\ \text { GTAM } & \text { Global technical Assistance Mechanism for Nutrition } \\ \text { HQ } & \text { Headquarter } \\ \text { IASC } & \text { The Inter-Agency Standing Committee } \\ \text { IFE/IYCF-E } & \text { Infant and Young Child Feeding in Emergencies } \\ \text { IFRC } & \text { The International Federation of Red Cross and Red Crescent Societies } \\ \text { IPC } & \text { Infection Prevention and Control } \\ \text { IRC } & \text { International Rescue Committee } \\ \text { LBW } & \text { Low Birth Weight } \\ \text { MAMI } & \text { Management of At-risk Mothers and Infants } \\ \text { MEAL } & \text { Monitoring, Evaluation, Accountability, and Learning } \\ \text { MICS } & \text { Multiple Indicator Cluster Surveys } \\ \text { MIYCN } & \text { Maternal, Infant, and Young Child Feeding } \\ \text { MSF } & \text { Medicine Sans Frontiers } \\ \text { MUAC } & \text { Mid-Upper Arm Circumference } \\ \text { OTP } & \text { Outpatient Therapeutic Program } \\ \text { PPE } & \text { Personal Protective Equipment } \\ \text { SFP } & \text { Supplementary Feeding Program } \\ \text { SMART } & \text { Standardised Monitoring and Assessment of Relief and Transitions } \\ \text { SMS } & \text { Short Message Service } \\ \text { UNHCR } & \text { United Nations High Commissioner for Refugees } \\ \text { WASH } & \text { Water Sanitation and Hygiene } \\ \text { WAZ } & \text { Weight for Age Z score } \\ \text { WHA } & \text { World Health Assembly } \\ & \end{array}$




\section{REFERENCES}

Burrell, Alice, and Hatty Barthorp. 2020. "GOAL’s experiences of management of at-risk mothers and infants (MAMI) programming in Ethiopia." Field Exchange 62:p30.

ENN, GOAL, LSHTM, and Save the Children \& collaborators. 2018. "C-MAMI Tool, Version 2 (2018)." https://www.ennonline.net/c-mami

Headey, Derek, and Marie Ruel. 2020. "The COVID-19 nutrition crisis: What to expect and how to protect." https://www.ifpri.org/blog/covid-19-nutrition-crisis-what-expectand-how-protect?fbclid=IwAR2jmt4eFQYS28J62-Onnt9LfaE0u1-hXP3xndzx0qkKRdB-YiKsmDWs4w

IASC. 2020. "Addressing mental health and psychosocial aspects of COVID-19 outbreak (Version 1.5)." https://interagencystandingcommittee.org/system/files/202003/IASC\%20Interim\%20Briefing\%20Note\%20on\%20COVID19\%20Outbreak\%20Readiness\%20and\%20Response\%20Operations\%20\%20MHPSS_0.pdf

IFE Core Group. 2017. "Infant and Young Child Feeding in Emergencies." https://www.ennonline.net/attachments/3127/Ops-G_English_04Mar2019_WEB.pdf

IFRC, IOM, UNHCR, and WHO. 2020. "Interim Guidance scaling-up COVID-19 outbreak readiness and response operations in humanitarian situations including camps and camp-like settings." https://interagencystandingcommittee.org/other/interimguidance-scaling-covid-19-outbreak-readiness-and-response-operations-camps-andcamp

Johns Hopkins University. 2020. "COVID-19 Dashboard by the Center for Systems Science and Engineering (CSSE) at Johns Hopkins University (JHU)." https://coronavirus.jhu.edu/map.html

Kerac, Marko, and Marie McGrath. 2018. "Management of Acute Malnutrition in Infants under 6 Months of Age." In The Biology of the First 1,000 Days, edited by CD Karakochuk, KC Whitfield, TJ Green and K Kraemer, 207-220. FL, USA: CRC Press.

Kluge, Hans Henri P., Zsuzsanna Jakab, Jozef Bartovic, Veronika D'Anna, and Santino Severoni. 2020. "Refugee and migrant health in the COVID-19 response." The Lancet 395 (10232):1237-1239. doi: 10.1016/S0140-6736(20)30791-1.

Spiegel, Paul. 2020. "How are refugees affected by COVID-19?" https://hub.jhu.edu/2020/04/20/covid-19-refugees-asylum-seekers/

The Lancet. 2020. "COVID-19 will not leave behind refugees and migrants." The Lancet 395 (10230):1090. doi: 10.1016/S0140-6736(20)30758-3.

UNHCR. 2020a. "COVID-19 SITUATION." http://reporting.unhcr.org/covid-19

UNHCR. 2020b. "Total refugee population in Ethiopia " https://data2.unhcr.org/en/country/eth/235

UNHCR. 2020c. "UNHCR Ethiopia | Gambella Camp profile - Kule refugee camp March 2020." https://data2.unhcr.org/en/documents/details/75364

UNHCR. 2020d. "UNHCR Ethiopia | Gambella Camp profile - Tierkidi refugee camp March 2020." https://data2.unhcr.org/en/documents/details/75365 
UNHCR. 2020e. "UNHCR Ethiopia | Gambella Infographics May 2020." https://data2.unhcr.org/en/country/eth/235

UNHCR. 2020f. "UNHCR Ethiopia Monthly Refugees and Asylum Seekers Population Demographics as of 31 May 2020." https://data2.unhcr.org/en/country/eth

UNHCR. 2020g. "UNHCR Ethiopia Weekly Operational Update 15 May 2020." https://data2.unhcr.org/en/documents/download/76357

UNICEF, GNC, and GTAM. 2020a. "Infant and Young Child Feeding in the Context of COVID-19" (Brief No. 2 (v1), 30 March 2020). https://mcusercontent.com/fb1d9aabd6c823bef179830e9/files/235ff424-1f6d-48c6a10aad5f631c7914/IYCF_Programming_COVID_19_Brief_2_v130March2020_for_distri bution.pdf

UNICEF, GNC, and GTAM. 2020b. "Management of Child Wasting in the Context of COVID-19" (Brief No.1, 27 March 2020). https://mcusercontent.com/fb1d9aabd6c823bef179830e9/files/e71f80cd-697f-4b00b6f5-88f310cf3fd2/Wasting_COVID19_Brief_1_27_March_v1_for_distribution.pdf

UNICEF, GNC, and GTAM. 2020c. "Nutrition Information Management, Surveillance and Monitoring in the Context of COVID-19" (Brief No. 3, 14 April 2020). https://www.ennonline.net/attachments/3414/Nutrition-Information-COVID19-Brief1_0_14-April.pdf

WHO. 2020a. "Rational use of personal protective equipment for coronavirus disease (COVID-19) and considerations during severe shortages" (Interim guidance 6 April 2020). https://data2.unhcr.org/en/documents/download/75543

WHO. 2020b. "Water, sanitation, hygiene and waste management for COVID-19" (Interim guidance 19 March 2020). https://www.who.int/publications-detail/water-sanitationhygiene-and-waste-management-for-covid-19

WHO. 2020c. "WHO Director-General's opening remarks at the media briefing on COVID19 - 11 March 2020." https://www.who.int/dg/speeches/detail/who-director-general-sopening-remarks-at-the-media-briefing-on-covid-19---11-march-2020 